\title{
HIGH LEVEL EDUCATION ON INTEGRATED WATER RESOURCES MANAGEMENT FOR SUSTAINABLE DEVELOPMENT
}

\author{
Juan Bautista Grau (D), Ana Maria Tarquis (iD, Juan José Martín-Sotoca (iD, José Manuel Antón \\ Universidad Politécnica de Madrid (Spain) \\ j.grau@upm.es,anamaria.tarquis@upm.es,jmartinsotoca@gmail.com,josemanuel.anton@upm.es
}

Received December 2017

Accepted July 2018

\section{Abstract}

Water, is in Spain a scarce commodity and although we have an age-old water culture, with an emblematic Court, such as the "Tribunal de las Aguas de Valencia", hydraulic infrastructure, hydrological basin plans, legislation and hydraulic administration since the 20th Century, there are problems of scarcity, water quality and extreme events that often lead to conflicts between users and also among the responsible administrations for their management. Within this framework, it is of a great interest the training of technicians in matters related to planning, quality and integrated water resources management for sustainable development.

In Argentina (especially in the NOA) and until a few years ago, water has not been considered as a scarce commodity. In addition to this, they do not have the history and culture of Spain on issues related to their management, planning and governance. Now, they have begun to establish laws and regulations, as well as, an Association of Consortia of Public Water Users, needing external advice. Therefore, it is necessary, to train technicians in water resources capable of working in areas related to their planning and sustainable management, with knowledge related to the quality required by users. These technicians could be integrated, both in the responsible water administrations', as well as, in private companies.

The project that is the object of this paper is based on preparing a double master's degree, in which the training needs of the students graduated of Spanish and Argentina Engineering Schools are taken into account.

Keywords - Education, Water management, Sustainable development.

\section{To cite this article:}

Grau, J.B., Tarquis, A.M., Martín-Sotoca, J.J., \& Antón, J.M. (2019). High level education on integrated water resources management for sustainable development. Journal of Technology and Science Education, 9(3), 295-307. https://doi.org/10.3926/jotse.361

\section{Introduction}

Water Resources are and will be throughout the XXI Century, as important or more, than Oil in the XX or the Coal in the XIX Century. Its integral management will be a priority matter, which will require welltrained experts to carry it out. 
Water, is in Spain a scarce commodity and although we have an age-old water culture, hydraulic infrastructure, hydrological basin plans, legislation and hydraulic administration, there are problems of scarcity, water quality and extreme events that often lead to conflicts.

In Argentina, especially in the NOA, (NW of Argentina) including the province of Salta, Figure 1, and until a few years ago, water has not been considered as a scarce commodity. In addition to this, they do not have the history and culture of Spain on issues related to their management, planning and governance. In part because although Argentina and Spain have similar population of 42 Million inhabitants and 46, but Argentina has an area of $2.780 .400 \mathrm{~km}^{2}$ and Spain of $505.990 \mathrm{~km}^{2}$. The Salta Province has 1.333 .365 inhabitants, $50 \%$ in Salta city, and $155.488 \mathrm{~km}^{2}$. It includes a part of the Andes chain of mountains, and has latitudes around $25^{\circ} \mathrm{S}$. Altitude has great ranges; at NE-E are areas at $300 \mathrm{~m}$ and at $\mathrm{W}$, an andine PUNA region with summits higher than $6000 \mathrm{~m}$. The Salta Capital has an altitude of $1200 \mathrm{~m}$. Some winds from South or SE made climate less hot and bring rain from 400 to $800 \mathrm{~mm} /$ year, with peaks of $1200 \mathrm{~mm}$ in high altitude places in SW. The rainfall in the area is monsoon-type, and it defines two distinct seasons: the rainy season from December to March (summer period)., presenting rains of short and torrential character. Bermejo River is the most important fluvial artery in the Province. It comes from higher Bolivia at North flowing to distant great Paraná River far at SE. The majority and more important rivers drain towards the Paraná through this region, such as Pilcomayo and San Francisco, that flows into Bermejo. Juramento or Salado, the Horcones and the rest like Itiyuro, Rio Seco, Dorado, Del Valle, Toro, etc are less in water but very important for the Province.

Within this framework, it is of a great interest the training of technicians in matters related to planning, quality and integrated water resources management for sustainable development.

This paper summarizes the project of a double master's degree, in which the training needs of the students graduated of Spanish and Argentina Engineering Schools are taken into account.
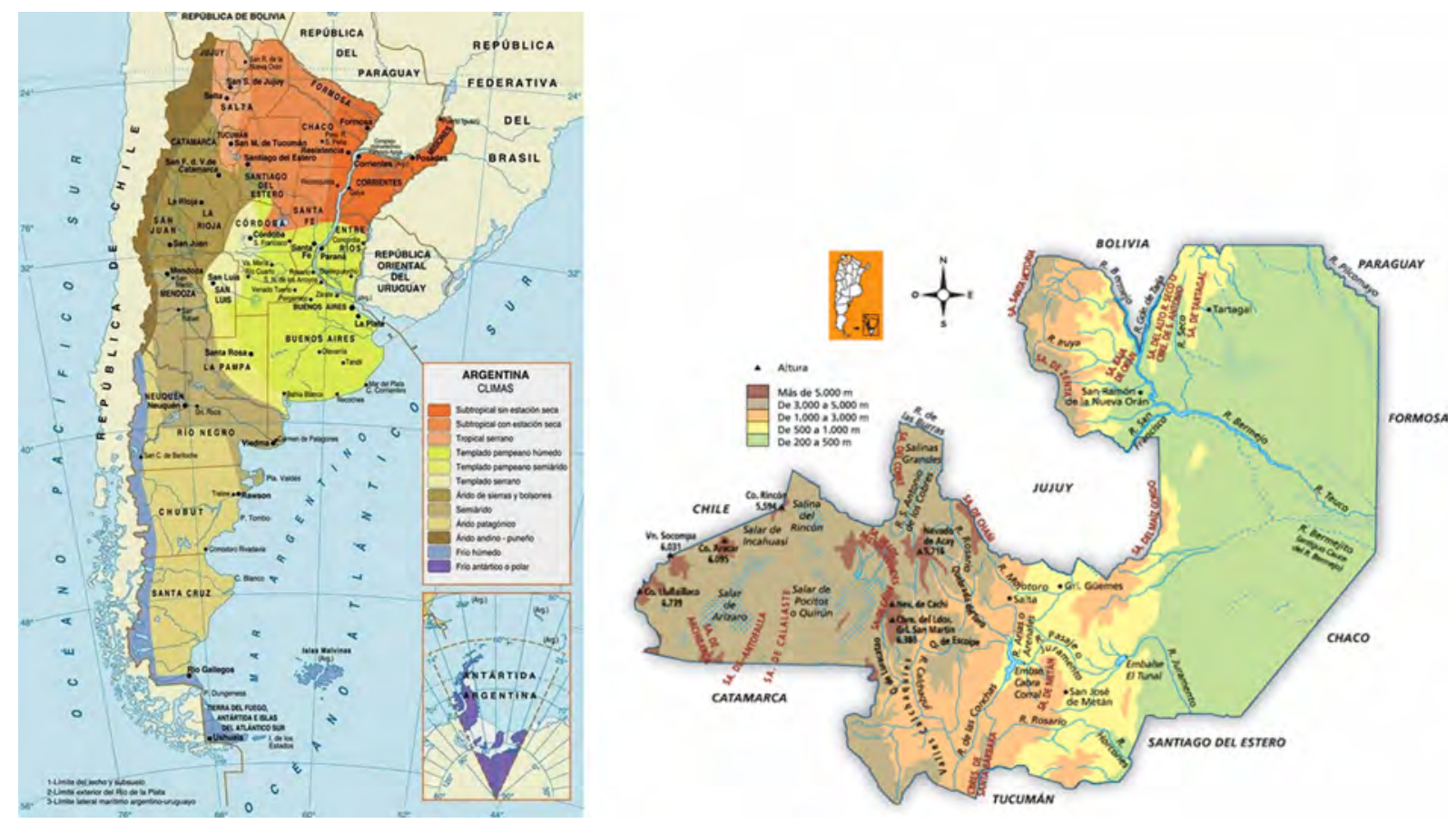

Figure 1. Argentina, Salta Province and Salta City

In the twenty-first Century, water resources (WR) are one of the top priorities worldwide. This is not only due to the need of this element for each one of the society sectors (agriculture, industry, residential use, etc.) but also, due to its great variability in time and space. The consequences of the lack, as well as the excess, can be dangerous, as the loss of productions by catastrophic floods and landslides. Besides, water 
pollution due to uncontrolled drainages carries out strong consequences for people's health, and also for the extinction of the natural habitat and the environmental risks. In most countries, the worry for the knowledge of the existent WR and its integral dealing has recently started within four fields: (1) The transformation into irrigable land, of huge extensions of dry land, due to a bigger demand of agriculture products, (2) the usage of water for leisure and tourism purposes, as in large areas where water was not used, the population has increased strongly by a factor of 10 , having installed golf courses, tourist, and residential areas, (3) bigger concerns about environmental issues, and (4) the mass-media pressure that derives from the climate change. For all that, new laws and rules for surface water and groundwater are coming up, as well as the creation of organisms to watch, standardize, and manage the water resource use. However, there is a problem that it is not always easy to deal with, since competences are spread and in many cases are confronted, being more important political and competence subjects than rational, technical, and economic.

\section{Examples of Needs in Salta, and a Case in Cordoba}

The authors from UPM of Madrid have relation with UCASAL of Salta, especially Dr. Juan Grau, and have participated with them in various studies and publications; and also with UNRC of Rio Cuarto. Some of the studies are examples about the need to improve knowledge and information about water resources management for Salta region and others, and we present some examples of them.

\subsection{Arenales River Plan}

Salta Province has $155000 \mathrm{~km}^{2}$ and 1 million population. It is at NW of Argentine (NOA), in the border with Bolivia, Chile and Paraguay, having latitudes around $25^{\circ} \mathrm{S}$ and it rains from 400 to $800 \mathrm{~mm} /$ year. It has a low density of population in small cities and native places "puestos" or "colonias". It has low standards for roads and its environment is "deteriorating progressively". Its Capital is the city of Salta, $1600 \mathrm{~km}$ from Buenos Aires and at $1187 \mathrm{~m}$ altitude. It concentrates half of the inhabitants of the province and has grown up to 600000 inhabitants, from a small active Spanish town founded in 1583.

The city is crossed by the Arenales River, Figure 2, going down from close mountains at West, source of water and end of sewers. But with its actual growing, this river, instead of a core of worthy for leisure and well-being, has become a focus of infection and of remarkable unhealthiness, and creates problems for the Government and society. Therefore, it is necessary to undertake a plan for the recovery of the river, directed to the attainment of the wellness and to improve the life's quality of the Community.

The fundamental idea of the plan is to obtain the arrangement of the river basin and an integral management of the channel and its surroundings, including the cleaning out. The improvement of the water's quality, the healthiness of the surroundings and the better off the environment, must go hand by hand with the development of sport activities, of relaxation, tourism, establishment of breeding grounds, picnic green areas, micro enterprises with clean production, and other actions that contribute to their benefit for society, being a basic factor for their care and sustainable use (Grau, Antón, Colombo, De los Ríos, Andina \& Tarquis, 2011).

In order to elaborate an integral plan, an initial matrix has been created with the criteria, alternatives and weights. Multicriteria Decision Methods (MCDM), Bayesian, Fuzzy methods and Compromise Program have been applied. This study will be developed with three suitable Discrete MCDM (Multicriteria Decision Methods) for classifying alternatives when the criteria are of rather different nature requiring some subjective assignation of values and weights. Two of them, the ELECTRE-I, (Roy, 1985; Roy \& Bouyssou 1993) used in environmental impact analysis, and PROMETHEE (Brans \& Vincke, 1985; Brans, Vincke \& Mareschal, 1986; Brans \& Mareschal, 1994) are outranking methods as using special ranking logics. A version of PROMETHEE modified and A.H.P. "Analytic Hierarchy Process" (Saaty T., 1980/1988, 1996a,b) will also be applied. These methods have been used in multiple agricultural and environmental applications. 
To carry out this important, heavy and long-term task a Commission will be created belonging to it, Experts coming from this Master and $\mathrm{PhD}$ from National and Católica Universities of Salta with the collaboration of UPM and government staff and private entities personnel.
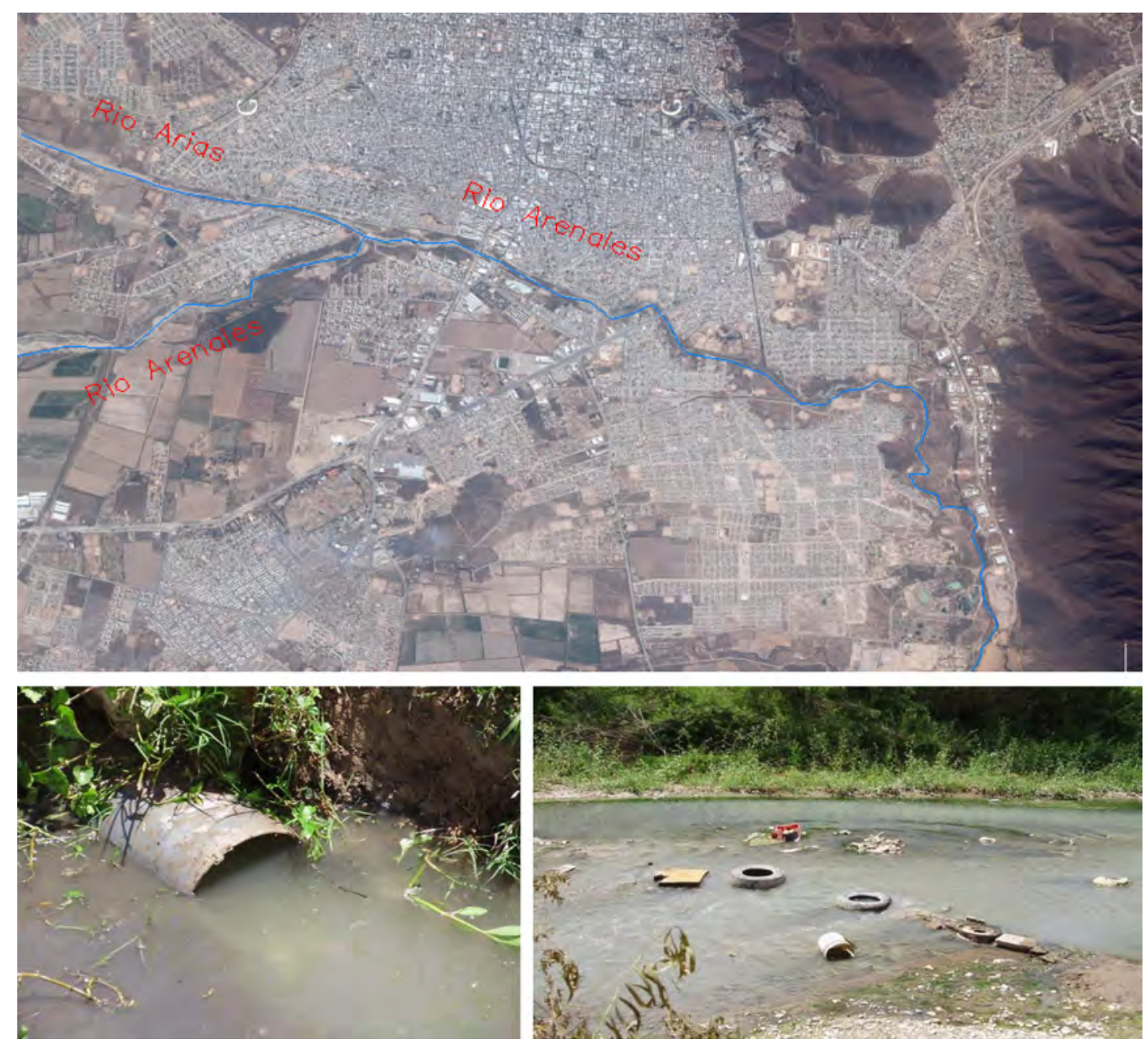

Figure 2. Arenales River

\subsection{Election of Water Resources Management Entity}

In the twenty-first Century, Water Resources (WR) are one of the top priorities worldwide. This is not only due to the need of this element for each one of the society sectors (agriculture, industry, residential use, etc.) but also, because of its great variability in time and space. The consequences of the lack of water as well as the excess can be dangerous, as the loss of productions by catastrophic floods and landslides. Besides, water pollution by uncontrolled drainages, carries out strong consequences for people's health, and also for the extinction of the natural habitat and the environmental risks. In most countries the worry for the knowledge of the existent WR and its integral dealing has recently started within four fields: (1) The transformation into irrigable land of huge extensions of dry land due to a bigger demand of agriculture products, (2) the usage of water for leisure and tourism purposes, as in large areas where water was not used the population has increased strongly by a factor of 10 , having installed golf courses, tourist, and residential areas, (3) bigger concerns about environmental issues, and (4) the mass-media pressure that derives from the Climate Change.

For all that new laws and rules for surface water and groundwater are coming up, as well as the creation of organism to watch, standardize, and manage the water resource use. 
However there is a problem that it is not always easy to deal with, as the competences are spread and in many cases are confronted, being more important political and competence subjects than rational, technical, and economic. In Valencia (Spain) "El Tribunal de las Aguas" ('The Water Jury') exists for more than 500 years, functioning as a model, being unique in the world. This model cannot be exported to other parts of the globe, because of the international intercommunity relationships. At the limit, one should have a special entity worldwide that could cope with all the competences and to delegate some of them to other national entities. The ideal is not reachable, but we must get it, as close as possible, and for that we will minimize the distance (Grau, Antón, Tarquis \& Andina, 2009).

\subsection{Toro River}

The Rosario - Toro River, Figure 3, rises in the mountainous area of Chañi and Muñano, and from the source up to the union with the Arias River, it covers a distance of approximately $210 \mathrm{~km}$. The Surface of the sub-basin Toro- Rosario is $4.779,9 \mathrm{~km}^{2}$ and its perimeter $532,6 \mathrm{~km}$. (Figure 4).

The regime of the rivers narrowly corresponds with the seasonal rain's variation. For this reason, the increasing ones take place between January and April. During the low water, the minimal flows are registered between September and November.

In March, the water requirement for irrigation is scanty compared with the four-month period of critical low water (August - November). Some dams have been constructed as the "Dique Las Lomitas" (6 $\mathrm{Hm}^{3}$ reservoir) on the Toro River, to regulate the utilization of the water.

The management of the irrigation system, currently, is in hands of the Consortium of Toro River System Users (Consorcio de Usuarios del Sistema Hídrico del Río Toro) belonging to Consortia Association.

The main problems are: deficient management of water resources, monoculture of Tobacco, lack of Marketing Channels, lack of infrastructures, needs of Industrial development, education, skilled manpower, adaptation to new agricultural production and social changes (Grau, Antón, Andina, Tarquis, Martín-Sotoca \& Colombo, 2016; PROSAP, 2011).

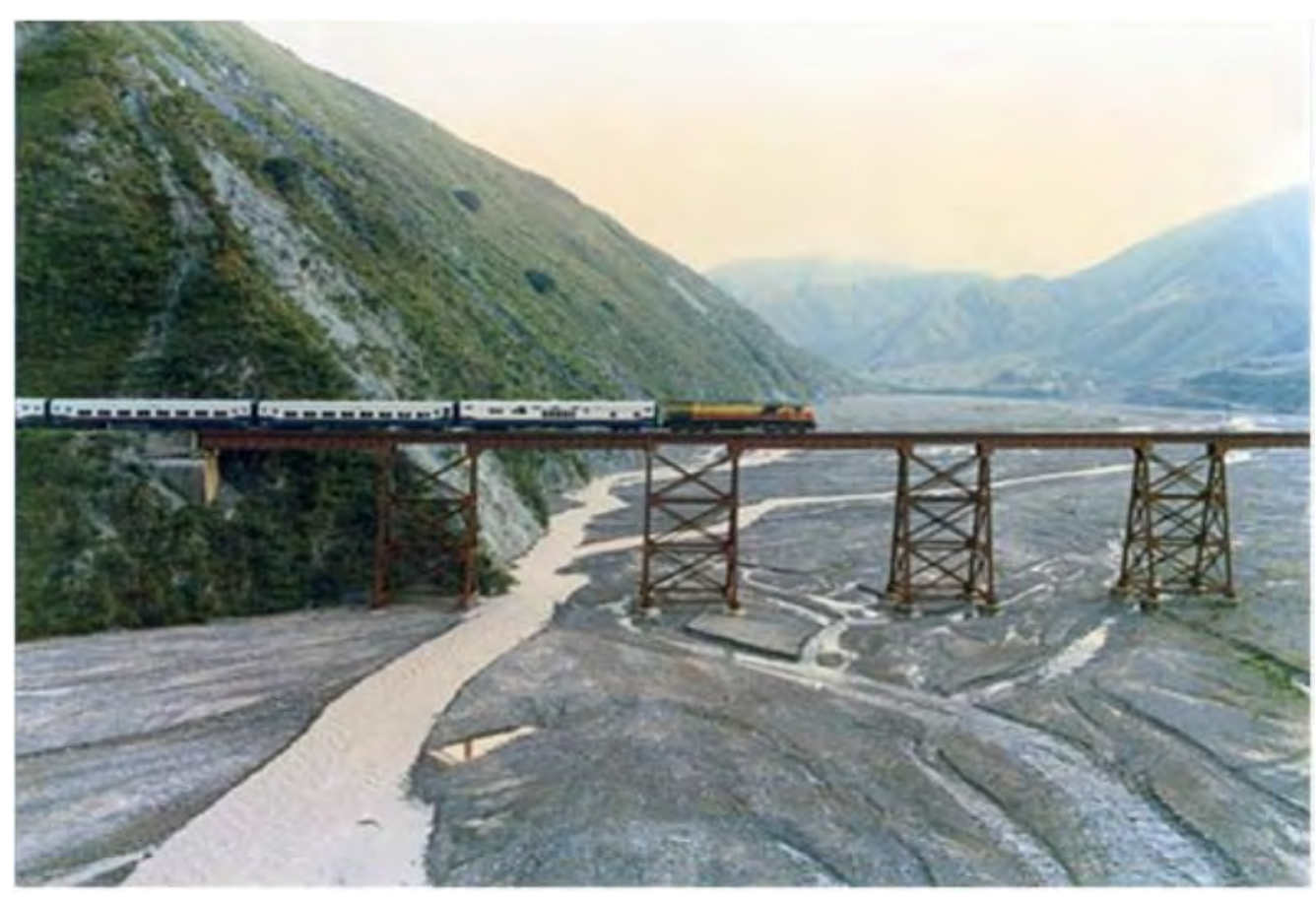

Figure 3. Toro River 


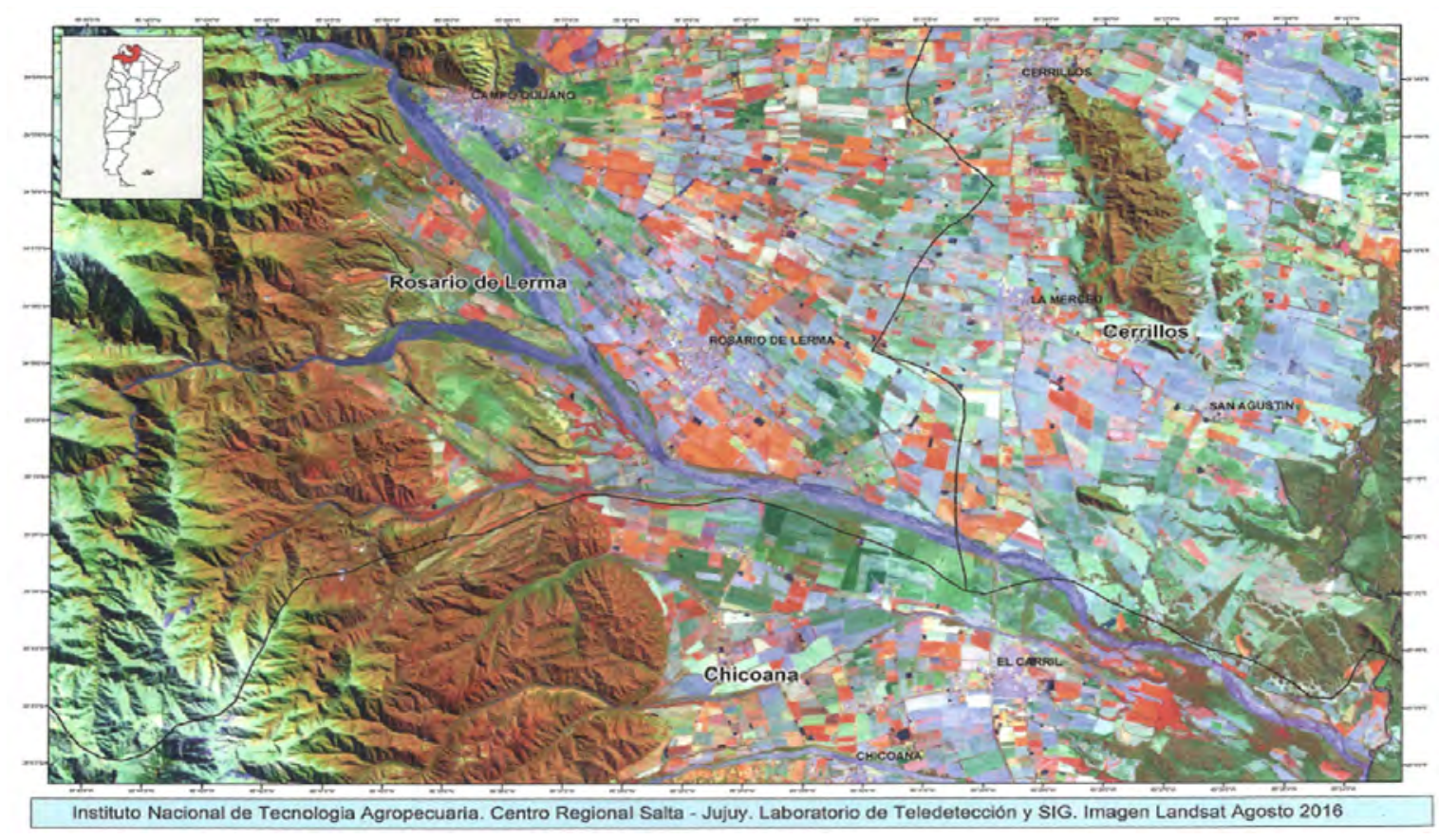

Figure 4. Toro River basin

\subsection{Land Use and Conservation Planning on Arroyos Menores (Río Cuarto, Province of Córdoba, Argentina)}

The study area $\left(6753 \mathrm{~km}^{2}\right)$ is the upper part of Arroyos Menores basin, Figure 5, containing sub-basins of Arroyos (sub-rivers) Santa Catalina $\left(2.304 \mathrm{~km}^{2}\right)$, “del Gato" $\left(2.406 \mathrm{~km}^{2}\right)$ and Ají $\left(2.043 \mathrm{~km}^{2}\right)$, that flow towards East and SE from an old chain of mountains. It has heights from 1000 to $260 \mathrm{~m}$. above sea level and becomes flatter and lower at West and SW, and it is at South of Province of Córdoba, which is in the centre of Argentine at West of Buenos Aires capital. It is in Rio Cuarto County, and Figure 5 indicates its position and form.

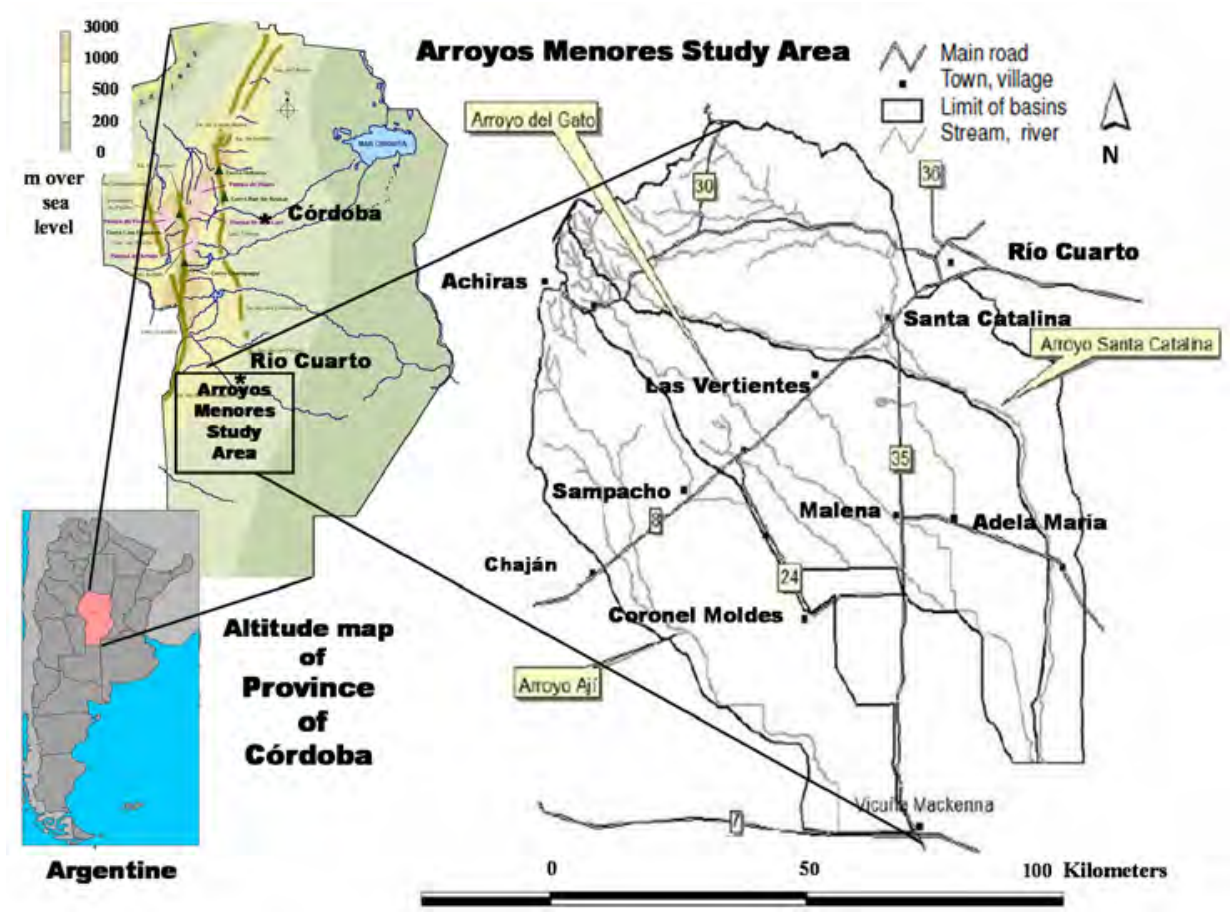

Figure 5. Location of study area "Arroyos Menores" in Argentina Republic 
It belongs to a larger "marginal Pampean northern region", it is distributed into fourteen distinct smaller sub-basins, and it suffers with the intensive water erosion in hill-slopes, gullies and streams. The population is dispersed in small villages, and Río Cuarto town ( $33^{\circ} 08^{\prime} \mathrm{S}$ lat; $64^{\circ} 20^{\prime} \mathrm{W}$ long), it is just out of it, at North, containing agro industry and services, and the UNRC University. The study area is rich for agriculture, with cereals and soybean, and also with cattle and with trees if slopes are higher. The use of land is evolving due to markets from lands owned by cultivators to the annual renting of lands to agro firms called here "contratistas" that produce, with few employees, winter wheat and transgenic soybean (Glycine max). The soybean crop has increased from 2012 because of a good demand from China and other products such as cattle decreased maybe because of taxes for exportation.

The study area landscapes look in centre as quite flat valleys, slopes are higher at North-West getting altitudes of 500 to $1000 \mathrm{~m}$ and a forest area, and they become lowlands at SE, and the area contains 4 geomorphologic units:

1. Mountains containing the rivers headwaters are part of Comechingones big chain formed by metamorphic rocks;

2. Piedmont strip with rocky and sediment soils, very undulating and highly erodible, now agricultural frontier;

3. Plains formed by agricultural loess with slope gradients varying between $3 \%$ to $0,5 \%$ from west to east, occupying a majority of the surface in form of flat basins of trees of streams;

4. Lowlands at SE are flat, flooding areas that receipt runoff and sediment from highland basins.

Climate is sub-humid with monsoon winds with a dry season (June to September), and $70 \%$ is concentrated of the $860 \mathrm{~mm} /$ year rain in hot semester (October to April). Rainfall intensity and erosion is high, with values reaching $100 \mathrm{~mm} \cdot \mathrm{h}^{-1}$ for $1 \mathrm{~h}$ rain duration. These loess soils are very fertile but suffer much from water erosions, and especially by regressive erosions that has created hundreds of gullies or "cárcavas" through them, such as in Figure 6, that are useless barriers that cut completely the surface apparently flat when looked from out. Some have more than $3000 \mathrm{~m}$ length, sometimes increasing $500 \mathrm{~m}$ in one year (Grau, Antón, Tarquis, Colombo, De los Rios \& Cisneros, 2010).

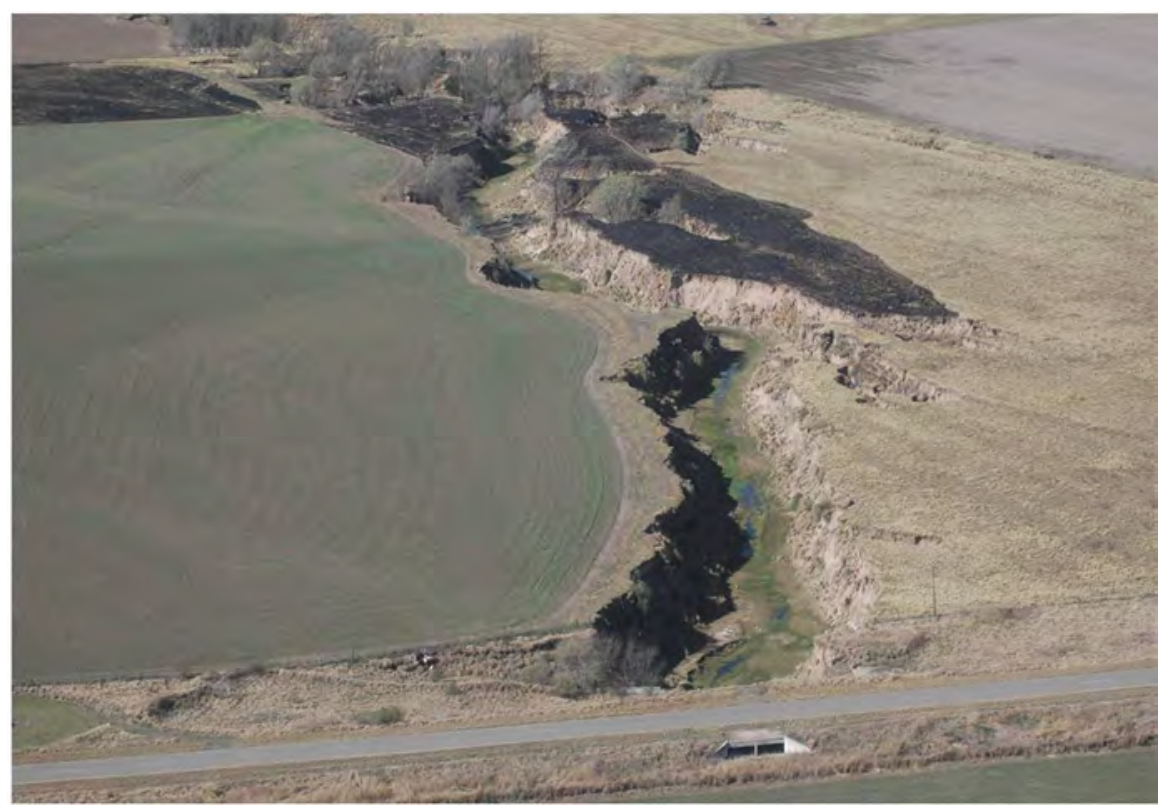

Figure 6. Regressive erosion gully in Arroyos Menores area

In plains, current soil use is most in agriculture and in lesser extent, livestock. The main environmental problems are water erosion in diverse forms: hill-slope erosion, high-bank or meander erosion in rivers 
showing poor geomorphic conditions, gully and wind erosion, sediment production and transport to lowland areas and dams, infrastructural damages, biodiversity lost, physical and chemical soil degradation due to intensified use. Potential problems to medium-term are chemical ( $\mathrm{N}$ and $\mathrm{P}$ ) non point pollution, reservoir sedimentation and rise of water table in lowland-located cities. Several plans in Arroyos Menores for Hydrological Management, combining binding canals with cover, control of active heads, forestation of basis of gullies, buffer bands of about $14 \mathrm{~m}$ wide, should be designed by specialists (Cisneros, Grau, Antón, de Prada, Cantero \& Degioanni, 2011).

DSS (Decision Support Systems) have to consider the complexity of consequences and of general ways of using the soils, and these DSS have to select a variety of criteria needing to use discrete multi-criteria methods, such as in (Grau et al., 2010) for the region of "Chaco Salteño" in Salta Province, that is at the North of Córdoba in Argentina.

Experts in discrete MCDM methods, conservation of soils and hydraulic management measures are recommended to recover the area actually sensibly degraded (Antón, Grau, Cisneros, Tarquis, Laguna, Cantero et al., 2016).

\section{Motivation}

The UPM and UCASAL signed a MoU (Memorandum of Understanding), in 2013 to establish a wide collaboration, promoting educational, administrative and academic exchanges.

Within the scope of this collaboration, which includes the exchange of academic personnel and students and the creation of courses at different levels, it has been thought that a good line would be the preparation of a partial attended dual master that, in addition to enabling the exchange, enhances the educational offer of both Institutions.

At present, in the degree programs of the different Faculties and Technical Engineering Schools, there are no complete training in this discipline, which contains both aspects intended for the sustainable planning of Water Resources, as those of water quality according to uses, and Governance and management. For all that, this Master tries to alleviate this deficiency, in both UPM and UCASAL.

The master will allow UCASAL to offer the experience that the UPM has in postgraduate courses. In addition, the proposed master is very useful not only for both Universities, but also for Spanish and Argentinean societies. For UPM, it completes the offer that already has in other disciplines, taking advantage of the potential of professionals with extensive experience in hydrology, hydraulics and water resources management, both at the University and in the Business Field.

In Salta and throughout the NOA (Northwest Argentine) there is no such thing, as in Spain, for our history, a culture and politics of water state. In this area, there are serious problems related to the management of Water Resources. Some were mentioned in the examples shown in point 2.

In Spain, in spite of the history and millenary culture of the water usage, we have territorial conflicts derived from the use of water. There are problems of distribution, having the subject pending of the autonomic transfers. The recently proposed National Hydrological Plan is not yet implemented and there is a need to improve irrigation and warning systems.

\section{Methodology}

Methodology is one of the most important parts of this Master, since they are involved two completely different Universities. One of them is the UPM (Universidad Politécnica de Madrid), www.upm.es, that is a very consolidated Public University, with a large number of Schools, some of them, such as "Caminos, Canales y Puertos Engineering" usually called "Civil Engineering" in other countries, which is more than 200 years old. All of them, with a large staff of $\mathrm{PhD}$ professors and researchers and a variety of masters and $\mathrm{PhD}$ programs. 


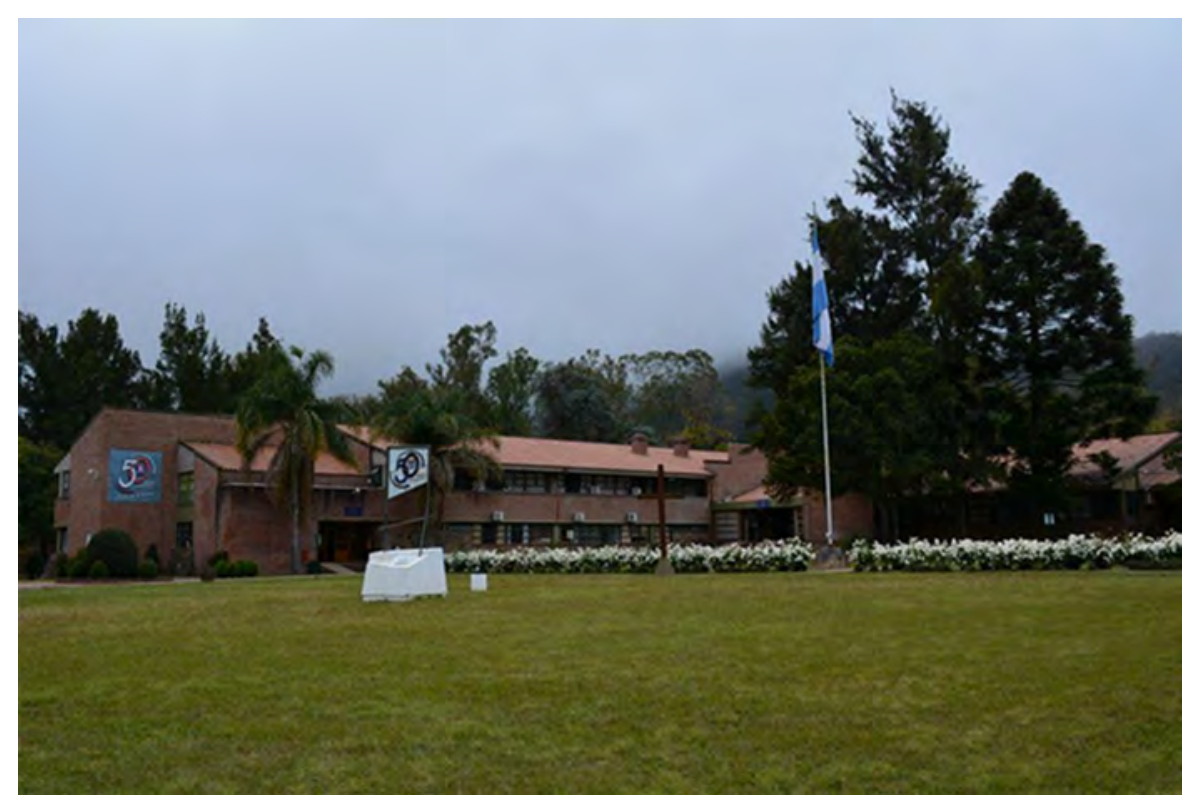

Figure 7. UCASAL (Universidad Católica de Salta)

The other one is UCASAL (Universidad Católica de Salta), www.ucasal.edu.ar, that is a Private University, which was founded about 50 years ago. In the area of Engineering offers Civil, Informatics, Industrial and Telecommunications Engineering. These Careers have been accredited and are being consolidated. They hardly have doctors in its cadre of professors and need to offer postgraduate courses. The first thing to do is to analyze the knowledge that students acquired when they graduated from both Universities. It must be taken into account that the title is double; therefore, when they finish the Master, all the students must have a similar training.

On the other hand, when a master is designed, we have to think about the target audience towards which it is directed to. This is imparted to cover some of the society needs, in both Public Administration and Private Industry, and should have enough quality to get sufficient students. In this case, due to the great difference in both geographic areas, it has been necessary to make a common part and other complementary one for students coming from Salta.

Another important aspect to consider is that one is at the Northern Hemisphere and the other is in the South, which brings in, an opposite school calendar and only coincides in the months of March, April, May, September, October and November.

One last aspect, not being least important, but on the contrary, it is the financial one. It is not easy to find funding for the trips of teachers and students, since it cannot be thought that they can be paid for with tuition. Enrollment will be done at both Universities, and students will be able to attend at either. That means that if a student from Salta obtains a scholarship or can afford to stay in Madrid, he can do the Master in the UPM and vice versa. One of the most important Scholarships Program for students and academics is the Erasmus Mundus. Argentina is included in this Program and for that it will be taken into account. The sponsors are other possibility considered like a funding via. In any case the Master titled could be obtained attending only to the classroom in Salta.

The practices in the laboratory, in the field and in Companies are an important part of the Master that should be carried out, both in Spain and in Salta. In the Argentine Northwest (NOA) there is a large deficit of professionals in Water Resources and Infrastructures, but there are a lot of Natural Resources and they can see the needs that have to be addressed, when the Master is finished. Also, there are large land extensions that could be irrigated, as well as hydrographic basin to be planned. In Spain, we have magnificent Laboratories, Hydraulic infrastructures, Hydrographic Confederations with good systems of data capture of Water Resources and alerts for prevention of catastrophic risks and companies dedicated 
to the management of these Water Resources. For all this, it should be convenient that the practices could be made for short periods of time both, in the NOA and in Spain.

All these conditions make that those who develop this Master have thought that should be semiclassroom; with one part in classroom, another one on-line and the third one out of class with practices in the field and in Companies. This Master at UCASAL premises will be taught by professors of that University, by professors of UPM, that will move in for a short period of time and, and by videoconference in the months in which the academic periods coincide.

The classroom period of UCASAL students in Spain and of the UPM students in Salta, will mainly be dedicated to the practical activities of subjects, technical visits and fieldworks. Because of the lack of financial resources, it will be made within a period of 15-20 days.

The Master programs and material will be published on line, by the MOODLE platform, to make them available to the students and professors. Also in class and out of class activities, the connectivity among students and professors will be established by this platform.

\section{Master Program}

\subsection{Thematic Areas}

The program is divided in three thematic areas:

1. Planning of Water Resources.

2. Water Quality and Sustainability of the Natural Environment.

3. Governance and Infrastructures in Water Resources.

\subsection{Subjects and Credits}

FIRST SEMESTER: (30 ECTS)

\begin{tabular}{|l|r|}
\hline \multicolumn{1}{|c|}{ SUBJECTS } & ECTS \\
\hline Surface Water Resources. & 4 \\
\hline Groundwater Resources. & 4 \\
\hline Data collection equipment for Water Resources. & 3 \\
\hline Data transmission networks for Water Resources. & 4 \\
\hline Treatment, Processing and Reporting systems of Water Resources. & 3 \\
\hline Warning networks for prevention of extreme events and risk management. & 4 \\
\hline Mathematical methods to aid decision-making. & 5 \\
\hline Applications of MCDM multi-criteria decision methods. & 3 \\
\hline
\end{tabular}

Table 1. Planning of Water Resources

\section{SECOND SEMESTER: (30 ECTS)}

\begin{tabular}{|l|r|}
\hline \multicolumn{1}{|c|}{ SUBJECTS } & \multicolumn{1}{c|}{ ECTS } \\
\hline Sustainable Territorial Planning. & 3.5 \\
\hline Actions for hydro-basin management. & 3.5 \\
\hline Analysis and water quality. & 5 \\
\hline Urban wastewater treatment. & 5 \\
\hline Water purification. & 4 \\
\hline Management and treatment of organic waste. & 5 \\
\hline Control of water erosion. & 4 \\
\hline
\end{tabular}

Table 2. Water Quality and Sustainability of the Natural Environment 
THIRD SEMESTER: (30 ECTS)

\begin{tabular}{|l|r|}
\hline \multicolumn{1}{|c|}{ SUBJECTS } & \multicolumn{1}{|c|}{ ECTS } \\
\hline Infrastructures for the distribution of water resources. & 3 \\
\hline Irrigation Methods and Systems. & 4 \\
\hline Environmental Impact Assessment. & 3 \\
\hline $\begin{array}{l}\text { Legislation on water issues and Entities responsible for planning and management } \\
\text { of water resources. }\end{array}$ & 5 \\
\hline Master's Thesis. & 15 \\
\hline
\end{tabular}

Table 3. Governance and Infrastructures in Water Resources

\subsection{Profile of Potential Students}

Potential priority students, but not exclusive, are: Engineers and Graduates in Agronomy and Agricultural Sciences; Graduates in Soil Sciences; Forestry and Forest Engineers and Graduates; Environmental Graduates; Civil Engineers; Telecommunication Engineers; Mining Engineers and Geologists.

The Master will be directed both to students who have finished the degree and wish to do the doctorate, as to professionals who currently work in the Administration or Companies in the agricultural and industrial sector related to water, the environment, waste management among others and who want to have a wider and deeper knowledge on water resources issues.

\subsection{Profile of Professors}

The Spanish professors belong to the Higher Technical School of Agronomic, Food and Biosystems Engineering, to the Higher Technical School of Telecommunication Engineers, Higher Technical School of Civil Engineers and Higher Technical School of Mining Engineers. They are PhD Agronomists and Telecommunication, PhDs in Chemistry and in Geology. They are Professors and Holders of University and with responsibilities in direction and University management.

They have a great experience in teaching, having taught for a great number of years, undergraduate and postgraduate courses and directed courses and seminars, both in Spain and abroad. In addition, there are many doctoral theses that have addressed both Spanish and foreign $\mathrm{PhD}$ students.

All of them belong to different Research Groups recognized by the Community of Madrid and are authors of a great number of articles on Water Resources Management, Territorial Planning in River Basin, Water Purification and Drinking Water, Cleaning out the Rivers, Integrated Management of Urban Solid Waste, Erosion and Environmental and the Climate Change issues in prestigious journals of the sector, such as Geoderma, Biogeosciences, ANOR among others and have published in Encyclopedias, such as Mathematics for Everybody, books and chapter books, to mention "Mathematical Models to Elaborate Plans for Adaptation of Rural Communities to Climate Change" from prestigious publishers.

They have participated in hundreds of International Congresses. Some of them are part of the Scientific Committees. They have presented and won projects in National and International Calls. They are also present in technology transfer with some patent and contracts with companies. Most of them have been distinguished with several university distinctions.

Others are professionals working in the Governmental Entities and in private companies evolving in the water management sector.

The UCASAL professors, who will participate in the initial phase of the master, are Doctors or Masters in different disciplines, such as: Experimental Ecology and Geobotany, Management and Environmental Impact, Economy and Business Administration and Geology. 


\section{Conclusions}

As we have seen, there is an undoubted need to program a Master of Integral Management of Water Resources, in both, UPM and UCASAL.

This master is launched to give content to the Memorandum of Understanding (MOU) of Collaboration in Teaching and Research activities, signed between both Universities. As it has been programmed, it fulfills the objective of training experts in all subjects related to the integral management of Water Resources: Experts in water quality, in its planning and management and in the treatment of contaminated water.

It also helps another of the objectives contemplated in the MOU, which is the mobility of students and teachers. It is very important that professors and disciples of UCASAL may have a stay of two weeks in the UPM, in the month of January, which is a not school period in Argentina. For students, to complete master's subjects with theoretical and practical classes and make visits to companies and institutions and study travels. For teachers, to improve their training and exchange experiences with the UPM colleagues. Likewise, UPM professors will complete the UCASAL teachers group. These professors, (it is estimated that 18), will teach for a week each one throughout the duration of the master.

The contacts maintained with Institutions, Companies, professionals and potential students have shown that there is a great interest in participating in this initiative.

Finally, the synergy to be established will result in an increase on the quality's teaching. The master program, the team of professors and the involvement of the university departments, institutions and companies, augur a bright future, excellence in teaching, learning, and research and that will probably lead to a $\mathrm{PhD}$ program.

\section{Acknowledgements}

We want to thank to UPM and UCASAL for the support to prepare this double master.

\section{Declaration of Conflicting Interests}

The authors declared no potential conflicts of interest with respect to the research, authorship, and/or publication of this article.

\section{Funding}

The authors received no financial support for the research, authorship, and/or publication of this article.

\section{References}

Antón, J.M., Grau, J.B., Cisneros, J.M., Tarquis, A.M., Laguna, F.V., Cantero, J.J. et al. (2016). Discrete multi-criteria methods for lands use and conservation planning on "La Colacha in Arroyos Menores" (Río Cuarto, Province of Córdoba, Argentina). Annals of Operations Research (ANOR), 245(1), 315-336. https://doi.org/10.1007/s10479-014-1606-6

Brans, J.P., \& Vincke, Ph. (1985). A Preference ranking Organization Method. The PROMETHEE Method for Multiple Criteria Decision-Making. Manage. Sci, 31(6), 647-656. https://doi.org/10.1287/mnsc.31.6.647

Brans, J.P., Vincke, Ph., \& Mareschal, B. (1986). How to select and how to rank projects: The PROMETHEE method. European Journal of Operation Research, 44(1), 138-228. https://doi.org/10.1016/0377-2217(86)90044-5

Brans, J.P., \& Mareschal, B. (1994). The PROMCALC and GAIA Decision Support System for Multi-criteria Decision Aid. Decision Support Systems, 12, 297-310. https://doi.org/10.1016/01679236(94)90048-5 
Cisneros, J.M., Grau, J.B., Antón, J.M., de Prada, J.D., Cantero, A., \& Degioanni, A.J. (2011). Assessing multi-criteria approaches with environmental, economic and social attributes, weights, procedures: A case study in the Pampas, Argentina. Agricultural Water Management, 98, 1545-1556.

https://doi.org/10.1016/j.agwat.2011.05.009

Grau, J.B., Antón, J.M., Tarquis, A.M., \& Andina, D. (2009). Election of water resources management entity using a multi-criteria decision (MCD) method in Salta province (Argentine). Journal of Systemics, Cybernetics and Informatics, 7(4), 1-7. (First presented in CITSA2008, Orlando, Florida USA.)

Grau, J.B., Antón, J.M., Tarquis, A.M., Colombo, F., De los Rios, L., \& Cisneros, J.M. (2010). Mathematical Model to Select the Optimal Alternative for an Integral Plan to Desertification and Erosion Control for the Chaco Area in Salta Province (Argentine). Biogeosciences, 7(11), 3421-3433. https://doi.org/10.5194/bg7-3421-2010

Grau, J.B., Antón, J.M., Colombo, F., De los Ríos, L., Andina, D., \& Tarquis, A.M. (2011). Mathematical Models for the arrangement and the cleaning of the river basin and surroundings of the Arenales river grounds to its passage by the city of Salta (Argentina). EGU General Assembly 2011. Vienna, Austria.

Grau, J.B., Antón, J.M., Andina, D., Tarquis, A.M., Martín-Sotoca, J.J., \& Colombo, F. (2016). Discrete multi-criteria methods for election of lands use alternatives in the Toro river hydro-basin (Province of Salta, Argentina).Oral presentation in $3^{\circ}$ International Congress of Water, Waste and Energy Management. Rome, Italy.

Munda G. (1995). Multicriteria evaluation in a fuzzy environment, Contributions to economics Series. Heidelberg: Physica Verlag. https://doi.org/10.1007/978-3-642-49997-5

PROSAP (Programa de Servicios Agrícolas Provinciales) (2011). Mejoramiento del Sistema de riego del Rio Toro. Argentina: Ministerio de Agricultura, Ganadería y Pesca de la República Argentina.

Roy, B. (1985). Méthodologie Multicritère d'Aide à la Décision, Collection Gestion, Série Production et techniques quantitatives appliquées à la gestion. Paris, France: Economica Ed.

Roy, B., \& Bouyssou, D. (1993). Aide Multicritère à la Décision: Méthodes et cas. Collection Gestion. Paris, France: Economica Ed.

Saaty, T. (1980/1988). The Analytic Hierarchy Process. New York: Mac Graw Hill.

Saaty, T. (1996a). Multicriteria Decision Making: The Analytic Hierarchy Process. AHP Series (extended edition) (Vol. 1). Pittsburg, USA: RWS Publications.

Saaty, T. (1996b). Decision Making for Leaders. AHP Series (extended edition) (Vol. 2). Pittsburg, USA: RWS Publications.

Published by OmniaScience (www.omniascience.com)

Journal of Technology and Science Education, 2019 (www.jotse.org)

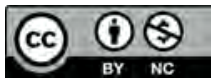

Article's contents are provided on an Attribution-Non Commercial 4.0 Creative commons International License. Readers are allowed to copy, distribute and communicate article's contents, provided the author's and JOTSE journal's names are included. It must not be used for commercial purposes. To see the complete licence contents, please visit https://creativecommons.org/licenses/by-nc/4.0/. 